\title{
Bone Mineral Density Assessed by Phalangeal Radiographic Absorptiometry Before and During Long-Term Growth Hormone Treatment in Girls with Turner's Syndrome Participating in a Randomized Dose-Response Study
}

\author{
THEO C.J. SAS, SABINE M.P.F. DE MUINCK KEIZER-SCHRAMA, THEO STIJNEN, \\ ARNE VAN TEUNENBROEK, WIBEKE J. VAN LEEUWEN, ANJALIE ASARFI, RICK R. VAN RIJN, \\ STENVERT L. DROP, AND THE DUTCH ADVISORY GROUP ON GROWTH HORMONE \\ Department of Pediatrics, Division of Endocrinology, Sophia Children's Hospital, Rotterdam, The Netherlands \\ [T.C.J.S., S.M.P.F.M.K-S., A.T., A.A, S.L.D.]; and the Departments of Epidemiology and Biostatistics [T.S.], \\ and Experimental Radiology [W.L., R.R.R.], Erasmus University, Rotterdam, the Netherlands
}

\begin{abstract}
To assess bone mineral density (BMD) in girls with Turner's syndrome before and during long-term treatment with $\mathrm{GH}$, longitudinal measurements using phalangeal radiographic absorptiometry were performed in 68 girls with Turner's syndrome. These previously untreated girls, age 2-11 y, participating in a randomized, dose-response trial, were randomly assigned to one of three $\mathrm{GH}$ dosage groups: group A, 4 $\mathrm{IU} / \mathrm{m}^{2} / \mathrm{d}(\approx 0.045 \mathrm{mg} / \mathrm{kg} / \mathrm{d})$; group B, first year $4 \mathrm{IU} / \mathrm{m}^{2} / \mathrm{d}$, thereafter 6 $\mathrm{IU} / \mathrm{m}^{2} / \mathrm{d}(\approx 0.0675 \mathrm{mg} / \mathrm{kg} / \mathrm{d})$; or group $\mathrm{C}$, first year $4 \mathrm{IU} / \mathrm{m}^{2} / \mathrm{d}$, second year $6 \mathrm{IU} / \mathrm{m}^{2} / \mathrm{d}$, thereafter $8 \mathrm{IU} / \mathrm{m}^{2} / \mathrm{d}(\approx 0.090 \mathrm{mg} / \mathrm{kg} / \mathrm{d})$. In the first $4 \mathrm{y}$ of GH treatment, no estrogens for pubertal induction were prescribed to the girls. Thereafter, girls started with $17 \beta$-estradiol ( $5 \mu \mathrm{g} / \mathrm{kg}$ body weight/d, orally) when they had reached the age of $12 \mathrm{y}$. BMD results were adjusted for bone age and sex, and expressed as SD scores using reference values of healthy Dutch girls. At baseline, almost every individual $\mathrm{BMD}$ value of bone consisting predominantly of cortical bone, as well as that of bone consisting predominantly of trabecular bone, was within the normal range of healthy girls and the SD scores were not significantly different from zero [mean (SE) $0.38(0.22)$ and $-0.04(0.13)]$. During 7 y of GH treatment, BMD SD scores showed a significant increase to values significantly higher than zero [mean (SE) $0.87(0.15)$ and $0.95(0.14)]$. The increment in BMD SD score of bone consisting predominantly of cortical bone was significantly higher in
\end{abstract}

\section{ABSTRACT}

group C compared with that of the other two GH dosage groups. The pretreatment bone age was significantly negatively related to the increment in BMD SD score. We found no significant influence of spontaneous puberty or the use of low-dose estrogens in the last $3 \mathrm{y}$ of the study period on the increment in BMD SD score during $7 \mathrm{y}$ of $\mathrm{GH}$ treatment. In conclusion, most untreated young girls with Turner's syndrome have a normal volumetric BMD. During $7 \mathrm{y}$ of GH treatment with 4,6 , or $8 \mathrm{IU} / \mathrm{m}^{2} / \mathrm{d}$, the BMD SD score increased significantly. (Pediatr Res 50: 417-422, 2001)

TS, Turner's syndrome

\section{Abbreviations:}

BMD, bone mineral density

RA, radiographic absorptiometry

DXA, dual energy x-ray absorptiometry

PA, posteroanteriorly

LAT, lateral

ROI, region of interest

$\mathbf{B M D}_{\mathbf{5 0} \%}$, bone mineral density of that part of the phalanx consisting predominantly of cortical bone (approximately 80\%) $\mathbf{B M D}_{\mathbf{2 5} \%}$, bone mineral density of that part of the phalanx consisting predominantly of trabecular bone (approximately 60\%)
Short adult stature and ovarian failure are the main features in TS $(1,2)$. Although girls with TS are not GH-deficient (3), many patients now receive $\mathrm{GH}$ treatment to increase adult

Received June 22, 2000; accepted March 23, 2001.

Correspondence: Theo C.J. Sas, M.D., Department of Pediatrics, Division of Endocrinology, Sophia Children's Hospital, Dr Molewaterplein 60, 3015 GJ Rotterdam, the Netherlands; e-mail: sas@alkg.azr.nl

Supported, in part, by Novo Nordisk A/S, Bagsvaerd, Denmark.

The participating members of the Dutch Advisory Group on Growth Hormone were Thom Vulsma, Emma Children's Hospital, Academic Medical Center, Amsterdam; Gera HoorwegNijman, Free University Hospital, Amsterdam; Cathrienus Rouwé, Beatrix Children's Hospital, Groningen; Guy Massa, Medical University Center, Leiden; Jos Gosen, Rijnland height. As most girls fail to initiate or progress through puberty, estrogen replacement is required. Our previous study showed that starting $\mathrm{GH}$ treatment at a relatively young age and beginning low-dose estrogen therapy from the age of $12 \mathrm{y}$ results in a normalization of height in most girls and pubertal development in conformity with their healthy peers (4).

Hospital, Leiderdorp; Willem-Jan Gerver, Academic Hospital, Maastricht; Bartho Otten, Sint Radboud University Hospital, Nijmegen; Ciska Rongen-Westerlaken, Canisius-Wilhelmina Hospital, Nijmegen; Sabine de Muinck Keizer-Schrama, Stenvert Drop, Sophia Children's Hospital, Rotterdam; Maarten Reeser, Juliana Children's Hospital, The Hague; Maarten Jansen, Wilhelmina Children's Hospital, Utrecht, the Netherlands. 
Despite limited reports of a greater number of fractures during childhood (5) or adulthood $(6,7)$, osteoporosis historically has been described as a feature in TS, because of the frequent observation of radiographic osteopenia and the coarse trabecular pattern of the carpal bones on radiographs (8). Because skeletal anomalies are common in females with TS, there has been speculation that an intrinsic bone defect as well as estrogen deficiency may explain these findings $(9,10)$. Although more refined methods such as single- and dualphoton absorptiometry and DXA have led to improved insights into BMD status in TS, these projection methods report areal and not true volumetric BMD, resulting in an underestimation of the true BMD in subjects with short stature (11). Thus, it would be preferable to measure the actual $\mathrm{BMD}$, e.g. by means of quantitative computed tomography (QCT). However, the radiation dose using QCT is far higher than that given using DXA. In addition, QCT is expensive and more difficult to use in pediatric practice. In contrast, phalangeal RA determines the BMD from a radiograph of the hand, which is already often made for the assessment of bone age $(12,13)$. Several studies in adults have shown that the RA method, using an aluminum wedge in the field of view to correct for differences in exposure and processing variables, is as good in predicting fracture risk as DXA (14-16).

To assess the volumetric BMD in young girls with TS before and during long-term treatment with recombinant human GH, longitudinal measurements using phalangeal radiographic absorptiometry were performed in 68 girls with TS, participating in a randomized, dose-response trial. The effect on height was described earlier (4). We now report the results of the BMD data over 7 y among three GH dosage groups.

\section{METHODS}

Patients and study design. Sixty-eight previously untreated girls with TS were enrolled in a multicenter GH dose-response study in the Netherlands. The diagnosis was confirmed by lymphocyte chromosomal analysis. Inclusion criteria were chronological age between 2 and $11 \mathrm{y}$, height below the 50th percentile for healthy Dutch girls (17), and normal thyroid function. Exclusion criteria were associated endocrine and/or metabolic disorders, growth failure caused by other disorders or emotional deprivation, hydrocephalus, previous use of drugs that could interfere with GH treatment, and spontaneous puberty (18). Written informed consent was obtained from the girls and their parents or custodians. The study protocol was approved by the ethics committee of each participating center.

After stratification for chronological age and height SD score for chronological age, girls were randomly assigned to the following groups: group $\mathrm{A}(n=23)$, receiving $4 \mathrm{IU} / \mathrm{m}^{2} / \mathrm{d}$ (equivalent to $0.045 \mathrm{mg} / \mathrm{kg} / \mathrm{d})$; group B $(n=23)$ receiving 4 $\mathrm{IU} / \mathrm{m}^{2} / \mathrm{d}$ in the first year, followed by $6 \mathrm{IU} / \mathrm{m}^{2} / \mathrm{d}(\approx 0.0675$ $\mathrm{mg} / \mathrm{kg} / \mathrm{d})$; or group $\mathrm{C}(n=22)$ receiving $4 \mathrm{IU} / \mathrm{m}^{2} / \mathrm{d}$ in the first yearr, $6 \mathrm{IU} / \mathrm{m}^{2} / \mathrm{d}$ in the second year, and thereafter $8 \mathrm{IU} / \mathrm{m}^{2} / \mathrm{d}$ $(\approx 0.090 \mathrm{mg} / \mathrm{kg} / \mathrm{d})$.

Recombinant human GH (Norditropin, Novo Nordisk A/S, Bagsværd, Denmark) was given s.c. once daily at bedtime using a pen injection system. Every $3 \mathrm{mo}$, the total GH dose was adjusted to the calculated body surface. According to the study protocol, treatment was stopped when subjects had grown $<1 \mathrm{~cm}$ over 6 mo. However, when girls were satisfied with their achieved height, they elected to stop GH treatment before study criteria for the termination of treatment had been reached. In the first 4 y of $\mathrm{GH}$ treatment, no estrogens for pubertal induction were prescribed to the girls. After $4 \mathrm{y}$ of $\mathrm{GH}$ treatment, estrogen therapy was started in the girls who were older than $12.0 \mathrm{y}$ of age; the younger girls started estrogen therapy at a yearly visit after reaching the age of $12 \mathrm{y}$. Five micrograms $17 \beta$-estradiol $/ \mathrm{kg}$ body weight $/ \mathrm{d}$, orally, were given in the first $2 \mathrm{y}, 7.5 \mu \mathrm{g} / \mathrm{kg} / \mathrm{d}$ in the third year, and 10 $\mu \mathrm{g} / \mathrm{kg} / \mathrm{d}$ thereafter. Cyclic progestogen therapy (Duphaston, Solvay Pharmaceuticals, Brussels, Belgium, $5 \mathrm{mg} / \mathrm{d}$ in the first $14 \mathrm{~d}$ of the month) was added after $2 \mathrm{y}$ of estrogen therapy. If puberty had developed spontaneously (Tanner breast stage $\geq 2$ ) during the study period and before start of estrogens, no estrogens were given.

Before the start of treatment (baseline) and subsequently every $3 \mathrm{mo}$, all girls were seen at their local hospital for measurements of height. Height was expressed as SD score using references of healthy Dutch girls (17). Body surface was calculated using the following formula: body surface area $=$ weight $^{0.425} \times$ height $^{0.725} \times 0.007184$ (19). Pubertal stages were assessed according to the method of Tanner (18). Before the start of the GH treatment (baseline), and subsequently once a year, standardized radiographs of the left hand were taken. Bone age was determined by two trained observers according to the Greulich and Pyle method (20).

Radiographic absorptiometry. The standardized radiographs of the left hand (PA) and the left index finger (LAT) were taken, on a single film using a dedicated cassette (Imation GTU film, $\alpha$-II Trimax intensifying screens, small $0.6-\mathrm{mm}$ focus, film focus distance $1.5 \mathrm{~m}, 45 \mathrm{kV}, 16 \mathrm{mAs}$, Ination International, Amsterdam, The Netherlands). Using these two projections, it is possible to adjust for soft tissue surrounding the middle phalanx and to assess the volume of this phalanx. Consequently, the BMD as a "true" volumetric density can be determined. With this technique, two measurement sites (ROIs) are used, the first ROI is at the midpoint of the line between the distal and proximal edge of the phalanx $\left(\mathrm{BMD}_{50 \%}\right)$, consisting predominantly of cortical bone (approximately $80 \%$ ); the second ROI is located at the proximal quarter-point of this line $\left(\mathrm{BMD}_{25 \%}\right)$, consisting predominantly of trabecular bone (approximately 60\%) (21). This technique has a short-term in vivo coefficient of variance of $<1 \%$, being slightly better than precision figures for the other RA techniques $(14,22)$.

For the application of this technique, two identical linear aluminum wedges were placed within the field of view of each exposure, i.e. one for the hand (PA) and one for the index finger (LAT), all x-rays were obtained in a strict, standardized fashion. Interactive software developed in-house was used to analyze all films, using a personal computer equipped with a modular frame grabber in combination with a charge coupled device (CCD) camera (SWK-31, DIFA Measuring Systems BV, Breda, The Netherlands, pixel size $37.5 \times 37.5 \mu \mathrm{m})$ ). Analysis, performed by one operator (A.A.), consisted of several 
steps. First, the system was calibrated on a daily basis by scanning a standard radiograph containing an image of the aluminum wedge, to correct for influences of variances in the transmitted light intensity. The second step involved scanning of the aluminum wedges (thickness $0-12 \mathrm{~mm}$ ), to calibrate the intensity values in the image. Then, the predefined ROIs were semiautomatically scanned to determine the distal and proximal edge of the second phalanx on the digitised x-ray image. The software then automatically determined the length and the outer contours of the phalanx and defined the two ROIs being 3-mm wide areas. These ROIs were placed on both the PA and LAT films. The software combined a volumetric BMD relative to the aluminum wedge.

Because chronological age may not be indicative of biologic development, especially in children whose disorder affects bone maturation, all measured values of $\mathrm{BMD}_{50 \%}$ and of $\mathrm{BMD}_{25 \%}$ were adjusted for bone age (20), and expressed as SD scores (SDS) using reference values of healthy Dutch girls. These reference values were previously described using a piece-wise linear regression analysis ("broken stick" technique). Reference values were only available for girls with a bone age $\geq 5.5$ y (13).

Statistical analysis. Results are expressed as mean and SD or SE, unless indicated otherwise. Differences between zero and the mean SDS at baseline or after 7 y were tested by one-sample $t$ tests. Because reference data were only available for girls with a bone age $\geq 5.5 \mathrm{y}$, it was not possible to calculate SDS of the youngest girls at baseline and in the first years of GH treatment, resulting in missing data. In addition, a number of girls discontinued GH treatment within the 7-y study period because of reaching adult height, causing missing values. Moreover, during the 7-y study period, for practical and technical reasons we could no longer obtain standardized $\mathrm{x}$-rays in a few centers. To estimate and test the effect of time, GH dose and other variables on the changes of $\mathrm{BMD}_{50 \%} \mathrm{SDS}$ and $\mathrm{BMD}_{25 \%}$ SDS during the 7-y study period, we used repeated measurement analysis of variance (RMANOVA) methods that used all available data (SAS Proc Mixed, SAS Institute, Cary, NC, U.S.A.). In these models, the yearly increase in $\mathrm{BMD}_{50 \%}$ SDS and $\mathrm{BMD}_{25 \%}$ SDS was the dependent variable. To investigate the differences between the three treatment groups, the GH dose was entered as a time-dependent categorical independent variable. To test the effect of pretreatment bone age on the changes in $\mathrm{BMD}_{50 \%}$ SDS and $\mathrm{BMD}_{25 \%}$ SDS, pretreatment bone age was added to the model. To assess the influence of spontaneous puberty and the influence of the use of estrogens on the changes in $\mathrm{BMD}_{50 \%} \mathrm{SDS}$ and $\mathrm{BMD}_{25 \%}$ SDS, these factors were entered as time-dependent covariates in the RMANOVA model. To investigate the association between the yearly increase in $\mathrm{BMD}_{50 \%}$ SDS and $\mathrm{BMD}_{25 \%}$ SDS with the yearly increase in height SDS, the latter was entered as a time-dependent covariate in the model as well. A $p$ value $<0.05$ was considered significant.

\section{RESULTS}

Three girls, one in each GH dosage group, dropped out of the study long before reaching adult height mainly because of noncompliance. In all three cases no problems with BMD were involved in the decision to discontinue the treatment. Data of these three girls were not used for the analysis of long-term GH treatment.

Table 1 lists the baseline clinical data of the remaining 65 girls. The three groups had similar initial characteristics. After 7 y of GH treatment, two girls in group A, six girls in group B, and four girls in group $\mathrm{C}$ had discontinued $\mathrm{GH}$ treatment because of reaching adult height or satisfaction with height achieved. For these girls, only data of the period during GH treatment were available for the 7-y analysis. In addition, in 14 girls ( $n=4$ in group A, $n=5$ in group $\mathrm{B}$, and $n=5$ in group C) there were missing values in the 7-y longitudinal data, because of the inability to obtain standardized $\mathrm{x}$-rays in a few centers.

After the first 4 y of GH treatment, 35 of the 65 girls started with estrogen therapy during the subsequent $3 \mathrm{y}$, whereas 5 girls did not receive estrogens because of spontaneous puberty. Twenty-five girls were prepubertal during the entire study period and had not started estrogen therapy because they were younger than $12 \mathrm{y}$ of age.

Figure 1 shows the individual values of $\mathrm{BMD}_{50 \%}$ and $\mathrm{BMD}_{25 \%}$, respectively, before and after $7 \mathrm{y}$ of $\mathrm{GH}$ treatment. At baseline, in 30 of the 65 girls, bone age was too low to compare with reference values. Most baseline $\mathrm{BMD}_{50 \%}$ and $\mathrm{BMD}_{25 \%}$ values of the remaining 35 girls were within the normal range and rather well distributed around the mean of healthy girls. Mean (SE) $\mathrm{BMD}_{50 \%}$ and $\mathrm{BMD}_{25 \%}$ SDS were $0.38(0.22)$ and $-0.04(0.13)$, respectively, being not significantly different from zero. After $7 \mathrm{y}$ of GH treatment, BMD data of 39 girls $(n=16$ in group A, $n=11$ in group $\mathrm{B}$, and $n$ $=12$ in group $\mathrm{C}$ ) were available. None of the $\mathrm{BMD}_{50 \%}$ and $\mathrm{BMD}_{25 \%}$ values after 7 y were below $-2 \mathrm{SD}$, and most values were higher than the mean of healthy girls. The mean SDS of the $\mathrm{BMD}_{50 \%}$, as well as that of the $\mathrm{BMD}_{25 \%}$ was significantly higher than zero [0.87 (0.15) and $0.95(0.14)$, respectively, $p<$ $0.001]$.

Table 2 shows the number of girls per year of whom SDS were available as well as the mean (SE) BMD SDS of these girls per year. All available data of the 65 girls were used in the repeated measurement analysis model to calculate the change in BMD SDS during the $7 \mathrm{y}$ of GH treatment. During $7 \mathrm{y}$ of GH treatment, the mean (SE) SDS of the $\mathrm{BMD}_{50 \%}$, as well as that of the $\mathrm{BMD}_{25 \%}$ had increased significantly compared with baseline values $0.53(0.16)(p=0.001)$ and $1.08(0.15)(p<$ $0.001)$, respectively. The increment in $\mathrm{BMD}_{50 \%}$ SDS was

Table 1. Mean (SD) baseline data for each treatment group. Karyotype (45, X; other) is expressed in number (percentage) of patients

\begin{tabular}{lccc}
\hline & Group A & Group B & Group C \\
\hline Number of girls & 22 & 22 & 21 \\
Chronological age & $6.1(2.1)$ & $6.7(2.4)$ & $6.5(2.4)$ \\
Bone age (GP) & $5.0(2.1)$ & $5.5(2.2)$ & $5.5(2.3)$ \\
Height SD score* & $-2.7(0.9)$ & $-2.4(1.0)$ & $-2.6(1.0)$ \\
Karyotype: 45, X & $18(82 \%)$ & $21(96 \%)$ & $16(76 \%)$ \\
Karyotype: other & $4(18 \%)$ & $1(4 \%)$ & $5(24 \%)$ \\
\hline
\end{tabular}

* References healthy Dutch girls.

${ }^{\dagger}$ Bone age according to the Greulich and Pyle method. 

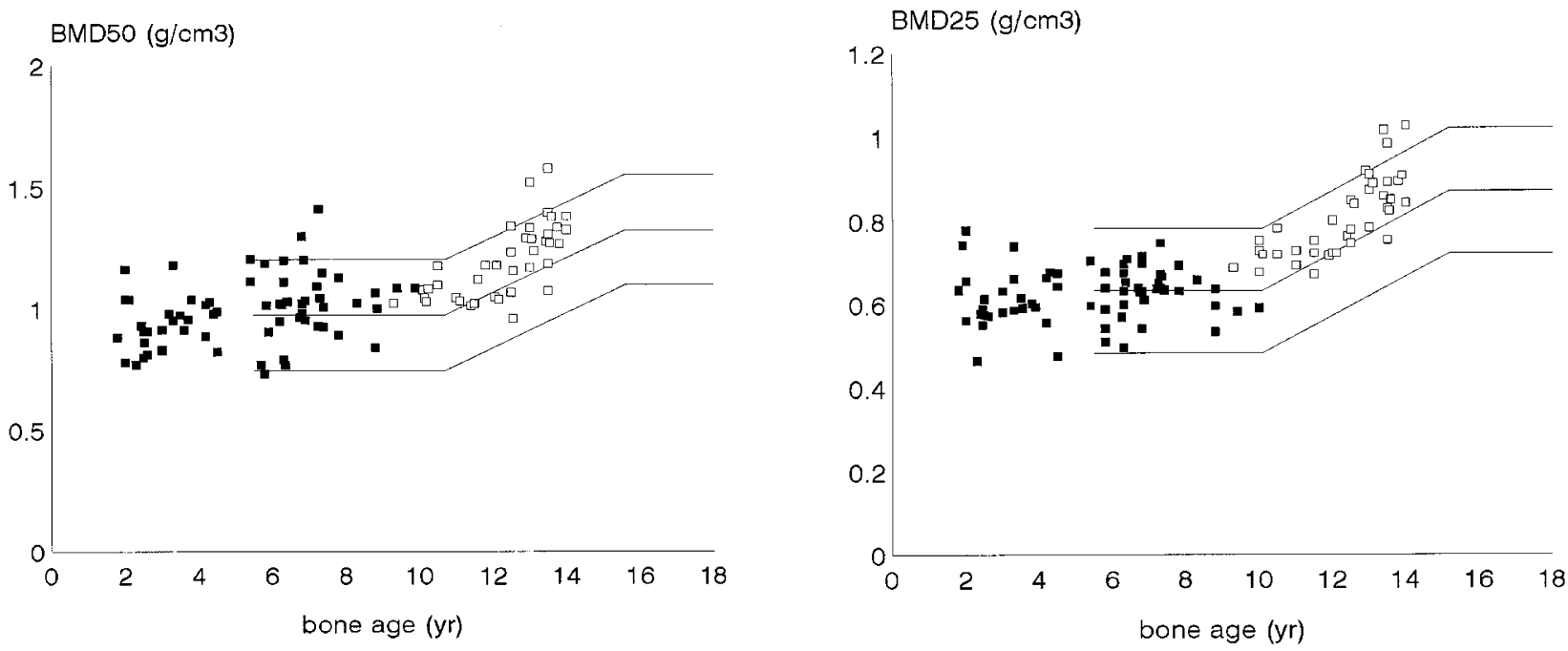

Figure 1. The individual $\mathrm{BMD}_{50 \%}$ values (left panel) and the $\mathrm{BMD}_{25 \%}$ values (right panel) before (filled squares, $n=65$ ) and after (open squares, $n=39$ ) $7 \mathrm{y}$ of GH treatment. The statistical analysis is performed using all data of the total group of 65 girls by RMANOVA. The mean and range ( -2 SD to +2 SD) of the reference data for healthy girls are indicated.

Table 2. The number of girls per year of whom SD scores were available and the mean (SE) BMD SD scores of the available data per year

\begin{tabular}{|c|c|c|c|c|c|c|c|c|}
\hline & \multicolumn{8}{|c|}{ Years of GH treatment } \\
\hline \multicolumn{9}{|c|}{$\mathrm{BMD}_{50 \%}$ SD score } \\
\hline Group B & $\begin{array}{l}-0.15(0.36) \\
(n=13)\end{array}$ & $\begin{array}{l}-0.12(0.26) \\
(n=16)\end{array}$ & $\begin{array}{l}0.28(0.23) \\
(n=17)\end{array}$ & $\begin{array}{l}0.31(0.16) \\
(n=20)\end{array}$ & $\begin{array}{l}0.28(0.20) \\
(n=21)\end{array}$ & $\begin{array}{l}0.34(0.25) \\
(n=15)\end{array}$ & $\begin{array}{l}0.41(0.23) \\
(n=13)\end{array}$ & $\begin{array}{l}0.79(0.19) \\
(n=11)\end{array}$ \\
\hline \multicolumn{9}{|c|}{$\mathrm{BMD}_{25 \%} \mathrm{SD}$ score } \\
\hline Group A & $\begin{array}{l}0.41(0.14) \\
(n=11)\end{array}$ & $\begin{array}{l}0.47(0.22) \\
(n=13)\end{array}$ & $\begin{array}{l}1.02(0.17) \\
(n=17)\end{array}$ & $\begin{array}{l}0.95(0.14) \\
(n=20)\end{array}$ & $\begin{array}{l}1.23(0.22) \\
(n=21)\end{array}$ & $\begin{array}{l}0.59(0.25) \\
(n=19)\end{array}$ & $\begin{array}{l}1.01(0.23) \\
(n=15)\end{array}$ & $\begin{array}{l}1.25(0.23) \\
(n=16)\end{array}$ \\
\hline Group B & $\begin{array}{l}-0.43(0.23) \\
(n=13)\end{array}$ & $\begin{array}{l}0.27(0.22) \\
(n=16)\end{array}$ & $\begin{array}{l}0.49(0.18) \\
(n=17)\end{array}$ & $\begin{array}{l}0.43(0.14) \\
(n=20)\end{array}$ & $\begin{array}{l}0.45(0.18) \\
(n=21)\end{array}$ & $\begin{array}{l}0.38(0.25) \\
(n=15)\end{array}$ & $\begin{array}{l}0.34(0.27) \\
(n=13)\end{array}$ & $\begin{array}{l}0.76(0.28) \\
(n=11)\end{array}$ \\
\hline Group C & $\begin{array}{l}-0.03(0.24) \\
(n=11)\end{array}$ & $\begin{array}{l}0.44(0.23) \\
(n=13)\end{array}$ & $\begin{array}{l}0.76(0.24) \\
(n=18)\end{array}$ & $\begin{array}{l}0.65(0.24) \\
(n=20)\end{array}$ & $\begin{array}{l}0.93(0.21) \\
(n=21)\end{array}$ & $\begin{array}{l}0.91(0.22) \\
(n=14)\end{array}$ & $\begin{array}{l}0.56(0.29) \\
(n=12)\end{array}$ & $\begin{array}{l}0.72(0.15) \\
(n=11)\end{array}$ \\
\hline
\end{tabular}

All available data of the 65 girls were used in the repeated measurement analysis model to calculate the change in BMD SD score during the 7 y of GH treatment.

significantly higher in group $\mathrm{C}(0.82)$ compared with group A $(0.45)$ and group B $(0.04)(p=0.025)$, without significant differences between groups A and B. No significant differences in the 7-y increment in $\mathrm{BMD}_{25 \%}$ SDS were found between the GH dosage groups (1.04 in group A, 0.99 in group B, and 1.30 in group $\mathrm{C} ; p=0.46$ ). Pretreatment bone age was significantly negatively related to the $7-\mathrm{y}$ increase in $\mathrm{BMD}_{50 \%}$ SDS and $\mathrm{BMD}_{25 \%} \operatorname{SDS}(\beta=-0.200, p<0.001$, and $\beta=-0.238, p=$ 0.001 , respectively). Neither the presence of spontaneous puberty or the use of estrogens, nor the 7-y increase in height SDS were significantly related with the yearly increase in $\mathrm{BMD}_{50 \%}$ SDS and $\mathrm{BMD}_{25 \%}$ SDS during $7 \mathrm{y}$ of GH treatment.

A total of 11 of 65 girls (three in group A, six in group B, and two in group $C$ ) had experienced a fracture during the study period: humerus $(n=1)$, wrist $(n=6)$, hand $(n=1)$, leg $(n=1)$, and foot $(n=2)$. The annual incidence rate for fractures of girls with TS was comparable with the published annual incidence of a reference population of healthy girls $<20$ $y$ of age [25 in 1000 (95\% confidence interval, 13 in 1000 to 44 in 1000) in the study group versus 19 in 1000 patient years in the reference population] (23). The mean (SE) SDS of $\mathrm{BMD}_{50 \%}$ and $\mathrm{BMD}_{25 \%}$ obtained on the visit close to the moment of fracture were $0.44(0.23)$ and $0.74(0.23)$, respectively. None of the values were below $-2 \mathrm{SD}$.

\section{DISCUSSION}

In this longitudinal study, volumetric BMD was assessed in relatively young girls with TS before and during long-term treatment with supraphysiological GH dosages. We show that most untreated young girls with TS have a normal volumetric BMD of the bone consisting predominantly of cortical bone, as well as that of bone consisting predominantly of trabecular bone compared with healthy girls. Our pretreatment data are in line with the data of Ross et al. (5), who found normal BMD values of the wrist (predominantly cortical bone) and the spine 
(predominantly trabecular bone) assessed by single-photon absorptiometry and dual-photon absorptiometry, respectively, after adjustment for height age in girls with TS with an age between 4 and $13 \mathrm{y}$. Thus, although skeletal abnormalities suggest an intrinsic bone defect in girls with TS $(9,10)$, this defect does not negatively influence BMD during childhood. In addition, the estrogen deficiency during childhood being present in most of the girls does not result in a low BMD during childhood.

During $7 \mathrm{y}$ of GH treatment, BMD SDS showed a significantly increment to values significantly higher than zero. The pretreatment bone age was significantly negatively related to the increment in BMD SDS: the younger the child at baseline, the better the 7-y increase in BMD SDS. We found no significant influence of spontaneous puberty, the use of low-dose estrogens, or the increase in height SDS on the increment in BMD SDS during 7 y of GH treatment. As in most GH trials in TS, no control group of untreated girls with TS was included in our study. Consequently, it is unknown whether the girls would have attained comparable BMD values after $7 \mathrm{y}$ if they had not received GH treatment. GH has both direct and indirect actions on bone. In animal models, GH stimulates osteoblast number and function and the production of various bone matrix factors (24). Paracrine activity of osteoblasts stimulates osteoclasts. Bone formation is enhanced preferentially to bone resorption during $\mathrm{GH}$ administration (24). In GH-deficient children, an increment in volumetric BMD was found after long-term GH treatment $(25,26)$. Lanes et al. $(27)$ assessed the BMD by DXA in prepubertal girls with TS while on GH treatment. The BMD of the lumbar spine (predominantly trabecular bone) was significant greater than in the control group of healthy children paired for bone age and height, whereas no differences in the BMD of the total body or femoral neck (predominantly cortical bone) were found. Neely et al. (28) reported BMD in prepubertal and pubertal girls with TS receiving GH treatment. Both lumbar and total body BMD and bone mineral apparent density were greater in the group with TS than in the control subjects matched for height. Shaw et al. (29) described the BMD of the lumbar spine measured by DXA in 14 girls with TS who had received GH and/or estradiol or no treatment. These girls had a normal baseline BMD, but a reduction in their BMD SDS after $2.5 \mathrm{y}$. No advantage was found for any form of treatment in optimizing bone mineralization. In the present study, we showed that the BMD of the bone consisting predominantly of cortical bone, as well as that of bone consisting predominantly of trabecular bone, increased significantly during GH treatment. Because we do not know the development of the BMD in untreated girls with TS, we cannot prove that the increment in BMD during treatment is the result of GH administration. However, the higher increment in BMD SDS of the "cortical" bone in the girls receiving the highest GH dose compared with the other two GH dosage groups suggests that GH treatment may have a positive effect on BMD.

Most girls with TS are estrogen-deficient during both their pre- and postpubertal years. It is well known that estrogens are required to attain a normal peak bone mass, which is a major determinant of osteoporosis later in life. Davies et al. (7) described the BMD in women with TS and in women with other causes of primary amenorrhoea, using estrogen replacement therapy in most of the cases. Both groups had severe osteopenia compared with healthy controls, after correction for weight and height. Because estrogen therapy was not started in most of these women until young adulthood, it was concluded that estrogen therapy should be instituted from an early age in patients with TS. In the present study, we show that low-dose estrogens in the fifth, sixth, and/or seventh year of GH treatment in 35 of the 64 girls did not significantly attribute to the increment in BMD SDS. A previous study on the effects of increasing estrogen dosages up to adult levels after discontinuation of GH treatment showed, however, that prolonged treatment with higher estrogen dosages than used in the present study does have a beneficial effect on BMD in girls with TS resulting in a normal adult BMD (30).

Only Ross et al. (5) reported a higher incidence of wrist fractures compared with healthy girls in a group of untreated prepubertal girls with TS with normal BMD. In the present study, we showed that the annual incidence rate for fractures in the girls with TS was comparable with that for a reference population of healthy girls. More data are available about the incidence of osteoporotic fractures in adults with TS. Davies et al. (7) showed a significantly higher frequency of fractures in women with TS than in a control group. Half of the fractures occurred at typical osteoporotic sites (wrist, spine, femoral neck). In addition, on the basis of data from a large database of women with TS, Gravholt et al. (6) reported an increased incidence of osteoporosis and fractures. Although insufficient estrogen therapy has a role in osteopenia, other factors, such as an intrinsic bone defect, may contribute to the increased risk of fractures in later life $(9,10)$.

In conclusion, most untreated young girls with TS have a normal volumetric BMD compared with healthy girls. During $7 \mathrm{y}$ of GH treatment with 4,6 , or $8 \mathrm{IU} / \mathrm{m}^{2} / \mathrm{d}$, the BMD SDS increased significantly. Only for the bone consisting predominantly of cortical bone was the 7-y increment in BMD significantly higher in the girls receiving GH doses up to $8 \mathrm{IU} / \mathrm{m}^{2} / \mathrm{d}$. Spontaneous puberty or low-dose estrogen therapy in the last $3 \mathrm{y}$ of the $7-\mathrm{y}$ study period in girls $\geq 12 \mathrm{y}$ of age did not significantly contribute to the increase in BMD. Because these girls have not attained their peak bone mass yet, follow-up into adulthood is required.

Acknowledgments. The authors thank Mrs. Ingrid van Slobbe, research nurse, for her assistance.

\section{REFERENCES}

1. Ranke MB, Pflüger H, Rosendahl W, Stubbe P, Enders H, Bierich JR, Majewski F 1983 Turner syndrome: spontaneous growth in 150 cases and review of the literature. Eur J Pediatr 141:81-88

2. Karlberg J, Albertsson-Wikland K, Naeraa RW, Rongen-Westerlaken C, Wit JM 1993 Reference values for spontaneous growth in Turner girls and its use in estimating treatment effects. In: Hibi I, Takano K (eds) Basic and Clinical Approach to Turner syndrome. Elsevier, Amsterdam, pp 83-92

3. Wit JM, Massarano AA, Kamp GA, Hindmarsh PC, van Es A, Brook CGD, Preece MA, Matthews DR 1992 Growth hormone (GH) secretion in Turner girls as determined by time series analysis. Acta Endocrinol 127:7-12

4. Sas T, Muinck Keizer-Schrama de S, Stijnen T, Jansen M, Otten BJ, Gera HoorwegNijman JJ, Vulsma T, Massa GG, Rouwé CW, Reeser HM, Gerver WJ, Gosen JJ, Rongen-Westerlaken C, Drop SLS 1999 Normalization of height in girls with 
Turner's syndrome after long-term growth hormone treatment: results of a randomized dose-response trial. J Clin Endocrinol Metab 84:4607-4612

5. Ross JL, Meyerson Long L, Feuillan P, Cassorla F, Cutler GB 1991 Normal bone density of the wrist and spine and increased wrist fractures in girls with Turner's syndrome. J Clin Endocrinol Metab 73:355-359

6. Gravholt CH, Juul S, Naeraa RW, Hansen J 1998 Morbidity in Turner syndrome. $\mathrm{J}$ Clin Epidemiol 51:147-158

7. Davies MC, Gulekli B, Jacobs HS 1995 Osteoporosis in Turner's syndrome and other forms of primary amenorrhoea. Clin Endocrinol (Ofx) 43:741-746

8. Bercu B, Kramer S, Bode H 1976 A useful radiologic sign for the diagnosis of Turner's syndrome. Pediatrics 58:737-739

9. Lubin MB, Gruber HE, Rimoin DL, Lachmann RS 1990 Skeletal abnormalities in the Turner syndrome. In: Rosenfeld RG, Grumbach MM (eds) Turner Syndrome. Marcel Dekker, New York, pp 281-300

10. Bachrach LK 1995 Osteopenia in Turner girls. In: Albertsson-Wikland K, Ranke M (eds) Turner Syndrome in a Life-Span Perspective. Elsevier, Amsterdam, pp 233-240

11. Gilsanz V 1998 Bone density in children: a review of the available techniques and indications. Eur J Radiol 26:177-182

12. Trouerbach WT, Grashuis JL, Zwamborn AW, Clermonts ECGM, Schouten HJA 1987 Microdensitometric analysis of bone structures in X-ray images. Skeletal Radiol 16:190-195

13. Van Rijn RR, Lequin MH, Van Leeuwen WJ, Hop WCJ, van Kuijk C 2000 Radiographic absorptiometry of the middle phalanx (dig II) in a Caucasian pediatric population: normative data. Osteoporosis Int 11:240-247

14. Ravn P, Overgaard K, Huang C, Ross PD, McClung M 1996 Comparison of bone densitometry of the phalanges, distal forearm and axial skeleton in early postmenopausal women participating in the EPIC study. Osteoporosis Int 6:308-313

15. Grampp S, Genant HK, Mathur A, Lang P, Jergas M, Takada M, Glüer CC, Lu Y, Chavez M 1997 Comparison of noninvasive bone mineral measurements in assessing age related loss, fracture discrimination, and diagnostic classification. J Bone Miner Res 12:697-711

16. Takada M, Engelke K, Hagiwara S, Grampp S, Jergas M, Glüer CC, Genant HK 1997 Assessment of osteoporosis: comparison of radiographic absorptiometry of the phalanges and dual X-ray absorptiometry of the radius and lumbar spine. Radiology 202:759-763
17. Roede MJ, Van Wieringen JC 1985 Growth diagrams 1980. Netherlands third nationwide survey. Tijdschr Soc Gezondh 63(Suppl):1-34

18. Tanner JM, Whitehouse RH 1976 Clinical longitudinal standards for height, weight, height velocity, weight velocity, and stages of puberty. Arch Dis Child 51:170-179

19. Dubois, Dubois 1916 Arch Intern Med 17:863-871

20. Greulich WW, Pyle SI 1959 Radiographic Atlas of Skeletal Development of the Hand and Wrist, 2nd Ed. Stanford University Press, Palo Alto, California

21. Trouerbach WT, de Man SA, Gommers D, Zwamborn AW, Grobbee DE 1991 Determinants of bone mineral content in childhood. Bone Miner 13:55-67

22. Yates AJ, Ross PD, Lydick E, Epstein RS 1995 Radiograph absorptiometry in the diagnosis of osteoporosis. Am J Med 2A:41S-47S

23. Boot AM, de Ridder MAJ, Pols HAP, Krenning EP, de Muinck Keizer-Schrama SMPF 1997 Bone mineral density in children and adolescents: relation to puberty, calcium intake and physical activity. J Clin Endocrinol Metab 82:57-62

24. Inzucchi SE, Robbins RJ 1994 Effects of growth hormone on human bone biology. J Clin Endocrinol Metab 79:691-694

25. Saggese G, Igli Baroncelli G, Bertelloni S, Barsanti S 1996 The effect of long-term growth hormone $(\mathrm{GH})$ treatment on bone mineral density in children with $\mathrm{GH}$ deficiency. Role of GH in the attainment of peak bone mass. J Clin Endocrinol Metab 81:3077-3083

26. Boot AM, Engels MAMJ, Boerma GJM, Krenning EP, de Muinck Keizer-Schrama SMPF 1997 Changes in bone mineral density, body composition, and lipid metabolism during growth hormone $(\mathrm{GH})$ treatment in children with GH deficiency. J Clin Endocrinol Metab 82:2423-2428

27. Lanes R, Gunczler P, Paoli M, Weisinger JR 1995 Bone mineral density of prepubertal age girls with Turner's syndrome while on growth hormone therapy. Horm Res 44:168-171

28. Neely EK, Marcus R, Rosenfeld RG, Bachrach LK 1993 Turner syndrome adolescents receiving growth hormone are not osteopenic. J Clin Endocrinol Metab 76:861866

29. Shaw NJ, Rehan VK, Husain S, Marshall T, Smith CS 1997 Bone mineral density in Turner's syndrome - a longitudinal study. Clin Endocrinol (Ofx) 47:367-370

30. Sas TC, de Muinck Keizer-Schrama SM, Stijnen T, Asarfi A, Van Leeuwen WJ, Van Teunenbroek A, Van Rijn RR, Drop SL 2000 A longitudinal study on bone mineral density until adulthood in girls with Turner's syndrome participating in a growth hormone injection frequency-response trial. Clin Endocrinol (Ofx) 52:531-536 